\title{
The Human Science Study of Nonhuman Animals ${ }^{1}$
}

\author{
Kenneth J. Shapiro
}

Psychologists for the Ethical Treatment of Animals

In an earlier work I described a phenomenological method based on the investigator's sensitivity to the experience of his or her body (Shapiro, 1985). By assuming various bodily reflective modes, the investigator locates his or her bodily sense of a phenomenon and utilizes that bodily present focus as a touchstone for the eventual description of that phenomenon. These investigatory postures delay the turn to language by beginning with the bodily sense of phenomena and slowly moving to a shape, then a diagrammatic space, and, finally, to metaphoric and linguistic explication of the object of study.

Recently, I have been extending that method to the study of nonhuman animals (Shapiro, in press b). The method is particularly fitting for their study in that it lingers with phenomena in the prelinguistic region of experience where animals largely live.

This article concludes with an application of this evolving method to the study of some features of the experience of a single animal, my dog Sabaka. The features explored are Sabaka's intentions and his "reading" of the intentions of others, notably of my intentions.

Before beginning, several personal contexts may be clarifying and perhaps not too self-indulgent. At present I am burdened with two commitments: the development of qualitative methods in the social sciences and the recognition of the rights of animals to more ethical consideration. I am particularly concerned with promoting less exploitive use of animals in science and education.

As its name suggests, by and large, human science has not concerned itself with either animals or their rights. Conversely, the philosophy of animal rights and an emerging science of animal welfare have not utilized rigorous qualitative method. However, particularly in this setting, I should pause to note that an earlier but still surviving tradition of continental biology and philosophy of biology with some affinity to the human sciences (several of its contributors influenced Merleau-Ponty) did at- 
tempt a qualitative approach to the study of animals. I refer to the work of von Uexküll, Buytendijk, Plessner, Goldstein (Grene, 1965), Katz (1937), and, more recently, Straus (Grene, 1965) and Lyons (1987).

Given my two commitments and their present disconnectedness, my reading of literature in the human sciences has taken on a Derridean deconstructive cast. The lack of reference to nonhuman animals I now read as a disruptive absence, a breach in the present order. For me now, following Foucault, the absence of other animals from these texts is a political act, a power play that defines nonhuman animals as an excluded, outcast class. The bestial take their alienated place with Foucault's leper, criminal, and "mad." To these significations of the absent as "other," to Derrida's other as rupturing "difference," and to Foucault's other as the oppressed, additionally and most importantly I find myself drawn to Levinas' "other"-the other who makes a claim on me. The specific claim here is to be responsible for animals and to liberate them.

I accept the sense in which any other being is other, whether my brother, you, or my dog. Methodologically, this means that I accept that our understanding of them is never transparent, for it is always an interpretative act. However, the present method attempts to move animals from the unspoken margin where they disrupt the present order through their continued absence, oppression, and claim on us to a more respectful place within the text.

I hope to show that extensions of human science methods can contribute to the study of nonhuman animals and that such methods are more respectful of animals than are traditional laboratory-based approaches.

The method I apply in this study of a single animal consists of three moves. The first two involve readings of, first, the social constructions within which the object of study and the investigator, here Sabaka and I, are embedded; and, second, of the individual history of the object of study, of Sabaka's history. The third is the critical reflective move and the one in regard to which I hope I am offering some advance. It requires being sensitive through one's own body to the postures, expressive movements, incipient intentions, and actions of the object of study. In phenomenological terms, the investigator is asked to inhabit or empathize with the bodily pole of an animal's experience in order to arrive at a sense of the world as experienced by the animal. This empathy is termed kinesthetic for it features a kind of bodily imitation and enactment by the investigator of 
the bodily movement and expression of the animal. The adequateness of this kinesthetic empathy is enhanced by extended involvement over time with the object of study, preferably through forming a relationship with the animal and participating with him or her in various activities.

The method is a mixed one in that it combines moves associated with a hermeneutic phenomenology with one more directly derivative of the phenomenology of Husserl and Merleau-Ponty. More particularly, the hermeneutic of the first two moves, the description of social construction and of individual history, inform the attempt at kinesthetic empathy. In this sense, the empathic move is an interpretative one, for it is contingent on the investigator's fore-understanding from the first two moves, as well as on the empathic work in progress. But having nodded to the presence of this hermeneutic circle, I also claim that empathy is a direct access to the experience of a nonhuman animal-although an access as limited and imperfect as in the case of a human animal. When we empathize with another sentient and mobile being, another lived body, we can directly apprehend his or her world. As it is with other human beings, our access to animals is by way of their lived body, for we have that in common with them.

\section{The Social Construction of Animal Being}

In this section I apply only that part of the hermeneutic that gets at the social construction of an animal. ${ }^{2} \mathrm{I}$ have selected a reading of "animal" more to demonstrate certain subtle forms that become the grounds of our oppression of animals than to advance the particular study of Sabaka presented in the final section. In particular, I describe two sociolinguistic sleights of hand that reduce the being of animal - the first from individual to species member and the second from species-specific being to generic animal.

As I write this section of this paper, I am distracted and upset. The Maine legislature is about to pass a bill which would promote the killing of coyotes by offering cash awards for the largest male, largest female, and the largest coyote killed. Together with other animal rights activists I have been calling legislators and the press in an attempt to defeat the bill. While those for and against are miles apart on the issue, I hear a common thread in their stories: Both redneck and yuppie agree that "The coyote is making a comeback in Maine." Note: "the coyote," not "coyotes." That apparently innocuous linguistic construction betrays a profound and insidious (for the welfare of animals) social construction. When we embody that sociolin- 
guistic construction, we live toward coyotes as a reified being, as that aggregate "the coyote in Maine." Any one coyote, then, is no longer that individual, the one I saw gamboling at dusk, or the one the hunter wounded after tracking him in the field across the way. That individual and that individuality are forgotten as the animal is reduced to a reference to the presence, the status, and even the intentions of a now reified aggregate, "The coyote is making a comeback in Maine"-as if all those coyotes within the borders of Maine moved as one federated organism, one supraindividual. In the same move the reification of the species dissolves the individual coyote and invests the aggregate of now nonindividuals with a kind of unified being that allows members of that species to be managed or harvested as if they were so much grass being mowed. ${ }^{3}$ This reification of the abstraction coyote species is part of what allows the probounty hunter to kill an individual coyote and the antibounty yuppie to limit his or her protest to, "That's not how I want to spend my tax dollars."

This way of living toward coyotes as if they were a "standing reserve" (Heidegger, 1977), a resource there waiting for our exploitation, may be contrasted to the place coyotes were given in the imagination of various American Indian groups. In many Amerindian creation myths a coyote is given a major role. For the northern Paiute, "In the old time Coyote was boss" (Guss, 1985 , p. 4). For the Karok, a coyote has a lead role in the creation of human beings: "Coyote ... lays down the law: Humans will eat salmon and acorns, but life will not be too easy" (Guss, 1985, p. 5). We find comparable roles in the mythology of the Navaho and Zuni Amerindians (Leydet, 1977, pp. 77-78)

In its critique of medical scholasticism, humanism defined individual in terms of free reason and located it exclusively in "human being." Partly as a foil, it distinguished this notion of rationality from the prerationality of animals. In this way a categorical gulf was created between human and now nonhuman animals, between rationality and its absence, and between individual and nonindividual or infraindividual being.

Whatever its origins, this social construction of an individual animal as a species is clearly an example of what the animal rightists call "speciesism." It is an attitude toward animals under whose auspices discrimination against individuals on the basis of their species membership is justified or even initiated. Both Ryder (1987), a British psychologist who coined it, and Singer (1975), an Australian philosopher who amplified on it, utilize the term to invoke parallels to racism and sexism, there- 
by legitimating the goals of the animal rights movement as the inevitable next ring in an expanding circle of compassion.

Racists and sexists clearly both discriminate against other individuals by denigrating a group of which those individuals are members. The present deindividuating attitude is a form of speciesism that justifies or initiates a comparable discrimination. In fact, in some ways the discrimination is even more insidious. When we speak of "the black" or of "women" our referent tends to be a stereotypic individual. However, when we speak of controlling the coyote population, or the market value of chicken, or even of going out and replacing our deceased black Lab pet dog with another, our primary referent is not an individual, or even an individual reduced to a denigrating cliché. It is an abstract supraentity, the species.

In the spirit of Heidegger's (1977) distinction, the deindividuation of animal is an ontological not an ontic reduction. While ontic is limited to the particular condition or experience of an entity, ontological refers to its more general being (or, more strictly, to a condition of the possibility of that general being). What is at stake in this construction of animal is not merely the loss of a particular individuality, of a particular style or feature of personal or social history that might construct an animal as an individual. The loss is of the possibility of being an individual and, of course, of all the protection of rights and standards that everywhere obtains for such an entity in our Western tradition.

A second common and equally insidious construction further reduces animal from a set of species-specific features to a generic animal, an organism, a set of purportedly general physiological or psychological processes. This second reduction is partly a creature of a positivistic approach to the natural sciences, which itself, at least in origin, is the handmaiden of an early humanistic and enlightened philosophy.

We can and do live toward an animal in a way that denies it its species identity as well as its individuality. (It seems the proper pronoun to reflect this reduction of animal to process.) Again, this attitude effects an ontological rather than ontic reduction in that the animal loses not just a particular species identity but the possibility of being any species.

While this second attitude originates and is more commonly assumed in the research laboratory, the following example features a wild animal, for I find the attitude more intuitively compelling in that context. 
A lion in a cage is not a lion. Of course, as we stare at the cage in which the animal is exhibited, we can imaginatively place it in the African savanna, lying near a thicket, having shared its kill with its pride and now licking its paws and enjoying its repose in a giant yawn. But even this most familiar species, this symbol of the hegemony of the wild itself, we as often experience in terms of the stereotypic behavior of any medium-sized to large-sized mammal permanently housed in a small cage. The repetitive pacing and rocking, the lack of interaction and interest in conspecifics and surroundings fail to evoke lion country. When our experience takes this turn, we are living toward this animal as a generic being, as neither a locus of individuality nor of species-specific being.

In the research lab, animals are also caged. In this setting they are permanently lived toward as objects of study. However, typically in both biomedical and psychological research, the object of study is a general process rather than a species-specific physiology or behavior. The animal is referred to as a "preparation" (Devereux, 1967) where what is being readied is not a rat, cat, dog, or chimpanzee but an organic or behavioral process. Whether through stereotaxic fixation or anesthetization or restraint in a Pavlovian sling, the preparation is an attempt to eliminate any individual or species identity and variability in order to disclose for study a general process, a biological organism, a generic animal.

Elsewhere I have argued that this attitude actually produces a generic animal and that we know an animal has been so reduced when it is chronically bored (Shapiro, in press a). When the relationship between the environment and the animal is chronically such that the animal has no interest in the environment, the habit-habitat unity that sustains and constitutes a species way has been split asunder and the lion, rat, or cat is no longer. The lion is "ex-hibited"-it no longer inhabits that country which it requires to be a lion.

This reduction to generic animal is a form of suffering that only human beings can produce, for, the spider's web notwithstanding, human beings are the consummate cage makers.

Here I take the cage as a metaphor for the dissolution of the habit-habitat unity constitutive of species being. However, ironically and it would seem unjustly, with the possible exception of systematic torture (Scarry, 1985), only nonhuman animals can suffer this particular ontological harm. Unlike nonhuman animals, human beings are not radically dependent on a speciesspecific habitat. Through his or her power of symbolic 
transformation, a human being in a cage is limited to ontic suffering. The loss and suffering of a lion without lion country, of a dog without a pack, of a bee without flowers is ontological as well as ontic.

\section{The History of Sabaka ${ }^{4}$}

It is late in the day and I am trying to finish some work that has taken me considerably longer than I anticipated. I become aware of Sabaka. From my study I can see him coming down the stairs in the hallway. He is moving with that slow, angled in ward cautious placement of one foot at a time. This is his gait when he has just woken up and is not yet fully mobilized. I recall now having walked past him three hours earlier while he was lying in his favorite spot on the landing. I had said to him, "You wait, Sabaka, I'll take the puppy"-a reference to our custom, now of many years, of going for a late afternoon walk together. My comment got little response as he continued to lie there, eyes opened, attentive but expressionless. I patted him in passing without breaking stride and he took a slightly longer breath, settling in, becoming slightly less vigilant. I realize now with discomfort that I failed to keep the promise.

He comes now almost to the threshold of my study and sits looking at me while he bends his head toward his right rear paw, which is raised motionless-possibly testing the activity of the fleas at the base of his ear. He does not scratch but goes down from the sitting position, slowly, to a passive crouch. As I now begin to close up shop, shutting down the computer, rustling papers, I am aware that he is watching me. At first he stays motionless with only his brown eyes following me as I move from desk to files. After a minute or two, he begins to change from this passive recline. He draws his stretched out forepaws in toward his face; he raises his haunches ever so slightly to a more action-readied position. Now he is posturally orienting not just his eyes but his whole body toward me as I move. His tail has some slight lift-incipient wag. As this develops, he is getting more restless, sighing, changing postures suddenly, almost jerkily. I feel the burden of his impatience and find myself geared more to readying the paraphernalia of our walk than to complying with my compulsive shop-closing protocol-so, walking boots, long-sleeved shirt, dog biscuits, whistle.

Now as I wander more broadly around the first floor, he is following me, tail lifted and wagging, bright eyed, up on his toes, a spring in his gait and, as our walk now is clearly imminent, occasionally punctuating his movement by a play invitation position (down on his front legs, up on his rear, sporadic short 
barks). When my moves take me toward the back door, he continues toward it even when I veer away to go to the coat rack to get my hat; he orients himself toward the door, prancing and looking back at me. When we are finally back at the door, he leaps up toward the latch again and again. (I am dimly aware of an undercurrent of self-reproach. Could my afternoon project have been important enough to postpone this? When had I last achieved this unadulterated and enthusiastically single-minded anticipation of anything?)

Once in the adjoining shed, sometimes I reach for the leash before letting him out and he carries it in his mouth. By now he is wagging so vigorously that most of his body is as tail-it half circles me, half directs me down the drive. At other times, when the red squirrel has come in from the woods to check the spillings at the birdfeeder, I open the exterior door with a "Where's that squirrel?" and Sabaka explodes like a thoroughbred out of the starting gate and makes a beeline, not for the presumptive presence of the squirrel at the feeder, but for the rear of the barn where he correctly anticipates the squirrel will make his leap from the roof to the trees for his escape.

After we cross into the field and are well away from the road, I take him off the leash and he sprints freely for a minute showing flashes of his former inexhaustible two-year-old self. In this way he quickly fans out across the hills to inspect the two or three already known woodchuck holes. He pauses at each, sometimes just sniffing with right paw raised, sometimes biting the turf at the entrance of the burrow. Then he assumes a more moderate coursing pace, nose down, tail almost 90 degrees to the ground, describing that peculiar pattern of quick minidirectional shifts by which he searches for fresh tracks.

Today something about his movement strikes me as different. He has stopped well before the woodchuck hole on the margin of the woods and has assumed that posture which I immediately recognize as mixed fear (ears back) and aggression (lips snarling) (Fox, 1974). Suddenly, a chase begins and I see him making broad loops across the back of the field down to the last hill before the intervale. He is running differently. It is neither the beeline for the red squirrel, nor the uncontrollable yapping after the cat after he suddenly comes upon him, nor the loping kangaroo-leaping when he is getting his bearings in the high grass. I stop noticing the difference when I see the prey, a red fox. Slightly panicky - for this is new prey and unknown outcome (I could never accept the chase as anything other than a game)-I grab for the leash and whistle, and lurch into my own middleaged broken saunter. For some reason, Sabaka goes off at a 
tangent; the fox pulls up short on the crest of a hill; I stop. The fox is looking at me for half a minute. I have many thoughts and feelings - I don't know him or her and wish I did, and wish him well, and worry about the traps my neighbor sets in the fall in the adjacent field. The fox turns and disappears over the hill. I fetch Sabaka.

\section{Reflection}

The above vignette lets me think through intention in a nonhuman animal, for in it it appears that Sabaka has the intention to go for his afternoon excursion. However, interestingly, this intention shows initially and most prominently in his apparent attention to my intentions. Does Sabaka have something akin to what has been called "second-order intention," an intention about another intention? For example, I intend to drink less often (Taylor, 1977, p. 18). Or, as here, does he have an intention about the intention of another being? For example, I intend to see if he intends to take me for a walk (Dennett, 1978, p. 173). More generally, then, this vignette directs me to attempt a double reading, a reading of Sabaka's reading of me. In a previous vignette/reflection, I discussed our relationship. Here, within that relationship, we ask what and how he knows me? What am I and how do I appear to Sabaka?

Sabaka comes and seeks me out so I will take him for a walk. In noticing that act, his seeking me out, I immediately understand it as I have just described. I ascribe to him an intentional act. The form of my description is an account of "what further (he is) doing in doing something" (Anscombe, 1957, p. 85). He seeks me out in order to go for a walk. I ascribe to him and I explain him in terms of intention. How do I know his is an intentional act? He does not tell me in words.

In various ways I know, each with its own contributing degree of confidence. I know because the explanatory style of my account of him as an "intentional system," to use Dennett's (1978) term, is a cohesive one. Further, it is one which allows me to make reasonably good predictions about his behavior. Still, a behaviorist could also provide a nonintentional account with reasonably good predictive power. I know because not only do I explain him as if he had an intention, I find myself actually living toward him as if he had such. But then at a very young age we impute soulful or animated or intentional being to virtually all objects. More personally still, for the moment taking me as the person, I know because in that moment his seeking me out pulls me out of my own project and makes me become aware of his project. In fact, in the first instant the effect on me 
of his act of seeking me out is that of Sartre's (1966) "look"-I become a being for him. With rare exceptions, celery stalks do not have that effect on me. Still, I am an animal lover, and perhaps I make a stronger distinction between celery and dogs than most other people.

Finally, one way I can know whether his is an intentional act is by empathizing with him. I can empathize with him in his act by focusing on his bodily comportment, posture, and action. I find I can gain a sense of his experience, here, of what he intends in seeking me out and, reflectively, that that act has the structure of an intentional act. I distinguish this intuition, this direct sensing, from an inferential mode of understanding.

Now I wish to further intuit: What is his sense of me? Sabaka comes, seeks me out, and watches me. As I have described in another context, he is riveted on me. What does he see, what is he watching for? Following Ricoeur (1981), can I say, What is his reading of me?

Recall his behavior vis-à-vis the squirrel. I open the door and he makes a beeline to the place where the squirrel leaps to liberty. His action here is anticipatory only in a weak sense of that term. He anticipates the trajectory of the squirrel's escape much as he veers as an animal he is chasing veers. He does not need to have a sense of the squirrel's action as intentional to do this. Arguably, he would follow the squirrel's anticipated track in the same way if the squirrel accidentally fell rather than intentionally fled. And does not he act the same way as a pup in chasing a leaf? Here, then, while Sabaka's action to catch the squirrel is intentional, it is a first-order intention only. Our empathic sense from his kinetics is that he is chasing in order to catch the squirrel. Our sense is not that he is chasing in order to catch the squirrel who, in Sabaka's experience, is running in order to get away.

But now again consider the example of the slower, more extended, and more interactive affair which is his seeking me out and watching me at our presumptive walk time. He is doing more than following the trajectory of my successive moves toward the boots, shirt, whistle, and leash. Particularly in the first moments he is watching to see if I intend to take him out. More than the simple extrapolation from the direction of my immediate movement, the range of his scrutiny is both broader and more articulate. Sabaka is sensitive to my bodily bearing, my attitude, my incipient movement, my gesture. He is sensitive to these as embodiments of any intention-am I readying myself to take him for a walk? And he is sensitive to these in the 
context of his first-order intention to watch me in order to go for a walk. This, then, is a second-order intention. How do I know he is watching me to read my intention?

First, two ways I know it indirectly, that is, by inference. I confess to having done an experiment with Sabaka, although I assure you one more playful than invasive or exploitive. The play consists of approximating, imitatively, those postures and incipient moves of mine that I suspect he scrutinizes in such moments. For example, I try to see how minimally I can direct myself to the preparation of taking Sabaka for a walk before he will show the excitement of his anticipated walk. In another context he is not fooled when I approach him as I would to be with him in a companionable way but say, "bad, Sabaka," mimicking my gruffest tone. It takes very little. A certain stirring at my desk, that to a less sensitive scrutinizer might as easily be read as a shift from one sore sedentary haunch to the other, he can read correctly as the beginnings of my intention to stop work. Of course, sometimes he is wrong-I mean sometimes, when I am not playing but am making some move within my work setting, he will misread a gesture on my part as an indication of my intention in regard to his walk.

At least I think he is wrong. At least I am aware of no such intention on my part in such a moment. But, and this is the second indirect way I am led to infer that his intention might be a second-order one, sometimes his obvious conviction that I am going to take him out promotes just that project in me. I do not make the further inference that his display of this conviction is an intended ploy on his part to manipulate my intention. ${ }^{5}$ However, I do infer from Sabaka's obvious responsivity to approximations to the bodily comportment of my intention to take him out that a sensitivity to that intention is a feature of his scrutiny of me. Still, I admit it is not a necessary inference: In a behavioristic account he could be highly discriminatory to behaviors that regularly accompany that intention.

More directly, and the preferred method here, that is, relying on kinesthetic empathy rather than inference, my sense of Sabaka is that he is sensitive to my intended action in a way that, while more sophisticated than the straight-line extrapolation of the trajectory of my movement, stops short of the capacity to empathize with my intended action. He does not have an intuition of my intention as lived, as it is for me in my experience. For him, I am not the subject of a world to which he can have access, as by contrast it is the burden of this paper to establish, I have access to his world. His sense of my intended action is, though, the relatively robust form of anticipation of the consequences of 
my intention. His is the practical knowledge or know-how that if I, his human companion, move this way, I will also make these other moves, the result of which will be a romp in the field for Sabaka.

In different terms, he cannot take me as an object in the full meaning of that predicate (Donceel, 1967, pp. 109-114). He cannot objectify me or my concerns as mine. I am an object of his consideration in the more limited sense of a means to his practical ends. I am a focal feature of a field organized entirely with respect to his needs and intention. He cannot refer to me, but he can use me. (It's all right. Sabaka, I forgive you.)

From most analytic philosophical points of view this is sufficient form of objectification for the possibility of a higher-order intention. Using Anscombe's (1957) language again, Sabaka acts intentionally on the basis of what further I am doing in doing something - that is, on the basis of my intentional action. Dennett (1978) explicitly attributes this higher-order intention to a nonhuman animal.

However, from a phenomenological point of view, we can make a further distinction, following From (1971). In our mundane perception of another individual, we distinguish a moment in which we perceive him or her as doing something for some further end (he is striking a match to light her cigarette) and one in which we empathize with his or her (perhaps here his romantic sense) of doing just that. In the first instance, the intention is implicit in the action sequence, in and as the implicit narrative it is unfolding. In the second, we are focally aware of the intention as it is present to the acting person himself or herself (p. 69). In the terms of our discussion, the distinction is between a more practical, consequence-oriented, and more empathic understanding. Here, we limit Sabaka to the former but take the position that even that practical orientation constitutes a perception of another's act as intentional. We conclude, then, that Sabaka is capable of second-order intention.

Dennett (1978) lists six conditions of personhood in ascending order of importance. Higher-order intention is the fourth, the fifth is verbal communication, and the sixth is self-consciousness (p. 270). By his account, then, Sabaka is a person by most accounts.

My reading, then, of this person's, of Sabaka's, reading of people like me is that he, Sabaka, is not a behaviorist, for he reads intentions. However, if he were a behaviorist, he would be Tolman, not Skinner. On the other hand, Sabaka, in his per- 
sonal style of reading, is not a phenomenologist, for while he is sensitive to intention he is not attuned to the intention of the other as lived. But if he were a phenomenologist he is closer to an investigator utilizing kinesthetic empathy rather than hermeneutic empathy. His relation to his object of study is closer to intercorporeity than intertextuality.

From Taylor's discussion of second-order volition (1977) as distinguished from second-order intention, it is clear that Sabaka lacks the self-reflective capacity for the former-he does not have wishes in regard to his own wants. For example, he does not wish he wanted to go for a walk less often. Taylor argues that such second-order volition is what gives relationships depth (p. 33). So is our relation, mine and Sabaka's, lacking depth? Certainly it is a less ambivalent relationship than other intimate relations I have known and, it follows, is less layered by contradictory pushes and pulls. It is also of itself less layered by shared interpretations, for it is not advanced or lived through reciprocal verbal communication. But is depth what it lacks? Cannot one layer be as thick as many? Do I love my son less deeply when he is a virtually preverbal two-year-old than when he is a chatterbox at three?

And is not a relation built on a history of reciprocal bodily intentions achieved across the barrier of interspecies otherness a deeply intimate relation?

\section{Conclusion and Implications}

The findings of the present study of an individual dog reveal that his is primarily a practical intelligence and sensibility. His know-how extends to a sensitivity to the body of another being. In particular, this dog Sabaka scrutinizes the body of a second individual and understands that individual's intentional acts vis-à-vis his own intention. This demonstrates a feature in a dog, second-order intention, which is commonly thought to be one constitutive condition for being a person.

The mixed method of the present study, combining hermeneutic and bodily empathic moves, has two general implications. The first is that the emerging human sciences can contribute to the productive and nonexploitive investigation of nonhuman animals. As investigators, we can respond to their claim on us not by excluding or marginalizing them as other but by attempting to understand them in a way that respects and allows their otherness, and as well both their individual and their speciesspecific identity. 
A second implication can be related more directly to pedagogy, particularly to the role of empathy in it. The literature in phenomenology consistently suggests that, almost from birth, a child is naturally empathic (Merleau-Ponty, 1964). A child is out there with the other in the sense that he or she is sensitive to the other's affect, gesture, and attitude. He or she smiles when the other smiles. Yet despite this beginning and the subsequent gradual development from this emotional contagion based on bodily resonance to a more robust and articulated ability to take the perspective of the other, we often lose or forget this empathic possibility.

Education involving our interaction with animals can contribute to this diminution in the powers of empathic understanding in at least two ways. First, we teach children a complex and confusing construction of classes of animals with which one can and should empathize and those with which one, supposedly, cannot-the rubber ducky in the bath that does not like to have soap in its eyes, but not the batter-wrapped chicken we fry and eat; the frog in the pond but not the one we dissect in the classroom. This social construction of excluded, distanced animals forms a basis for their deindividuation and "despecification."

More subtly, when we force children as early as their grade school years to dissect an animal, we are teaching them to unlearn empathy itself as a way of understanding. ${ }^{6}$ Dissection teaches that to understand an animal or any entity we must cut it up into parts. Part making and part learning replaces knowing the animal by the intimate move of bodily empathizing with his or her behavior, posture, gesture, and intention.

\section{Notes}

1. This paper was originally drafted for presentation at the Human Science Research Conference in Aarhus, Denmark, August 1989. For personal reasons, I was unable to give the paper. It is presented here with some modifications.

2. I have presented a history of Sabaka elsewhere (Shapiro, in press b).

3. Elsewhere, I have described one origin of this deindividuation of nonhuman animals in modern humanistic philosophy (Shapiro, in press $c$ ).

4. In an earlier work, I described the present method and its application - the latter in the form of three vignettes and my reflections on them (Shapiro, in press b). Here, I present a fourth vignette, again featuring my dog Sabaka.

5. Dennett (1978) does describe a dog who, apparently deceitfully, scratched the door in order to get her human companion to get 
up to let her out in order to climb into the preferred chair he had been occupying (p. 275).

6. See "The Pedagogy of Learning and Unlearning Empathy" in this issue.

\section{References}

Anscombe, G.E.M. (1957). Intention. Ithaca, NY: Cornell University Press.

Dennett, D.C. (1978). Brainstorms. Cambridge, MA: MIT Press.

Derrida, J. (1976). Of grammatology (G.C. Spivak, Trans.).

Baltimore: Johns Hopkins University Press.

Devereux, G. (1967). From anxiety to method in the behavioral sciences. Paris: Mouton.

Donceel, S.J. (1967). Philosophical anthropology. Kansas City: Sheed Andrews and McMeel.

Foucault, M. (1973). The order of things: An archaeology of the human sciences. New York: Vintage.

Fox, M.W. (1974). Understanding your dog. New York: Bantam Books.

From, F. (1971). Perception of other people. New York: Columbia University Press.

Grene, M. (1965). Approaches to a philosophic biology. New York: Basic.

Guss, D.M. (1985). The language of birds. San Francisco: North Point Press.

Heidegger, M. (1977). The question concerning technology and other essays. New York: Harper \& Row.

Husserl, E. (1970). Cartesian meditations. The Hague: Martinus Nijhoff.

Katz, D. (1937). Animals and men: Studies in comparative psychology. London: Longmans, Green.

Levinas, E. (1969). Totality and infinity. Pittsburgh: Duquesne University Press.

Leydet, F. (1977). The coyote: Defiant songdog of the west. San Francisco: Chronicle Books.

Lyons, J. (1987). Ecology of the body. Durham, NC: Duke University Press.

Merleau-Ponty, M. (1962). Phenomenology of perception. New York: Humanities Press.

Merleau-Ponty, M. (1964). The child's relation with others. In J.M. Edie (Ed.), The primacy of perception (W. Cobb, Trans.).

Evanston, IL: Northwestern University Press.

Ricoeur, P. (1981). Hermeneutics and the human sciences. New York: Cambridge University Press.

Ryder, R.D. (1987). Victims of science: The use of animals in research. London: Davis-Poynter.

Sartre, J.-P. (1966). Being and nothingness. New York: Washington Square Press.

Scarry, E. (1985). The body in pain. New York: Oxford University Press. 
Shapiro, K.J. (1985). Bodily reflective modes: A phenomenological method for psychology. Durham, NC: Duke University Press.

Shapiro, K.J. (in press a). The death of the animal: Ontological vulnerability and harm. Between the Species.

Shapiro, K.J. (in press b). Understanding dogs through kinesthetic empathy, social construction, and history. Anthrozoös.

Shapiro, K.J. (in press c). Animal rights v. humanism: The charge of speciesism. Journal of Humanistic Psychology.

Singer, P. (1975). Animal liberation. New York: New York Review. Taylor, C. (1977). What is human agency? In T. Mischel (Ed.), The self: Psychological and philosophical issues (pp. 103-135).

Oxford: Blackwell. 